\title{
Colorectal Cancer Patient Characteristics, Treatment and Survival in Oman - a Single Center Study
}

\author{
Shiyam Kumar ${ }^{1 *}$, Ikram A Burney ${ }^{1}$, Khawaja Farhan Zahid ${ }^{1,}$ Philomena \\ Charlotte D Souza ${ }^{2}$, Muna AL Belushi ${ }^{2}$, Taha Dawood Mufti ${ }^{1}$ Waeil AL Meki ${ }^{1}$, \\ Muhammad Furrukh ${ }^{1}$, Mansour S AL Moundhri ${ }^{3}$
}

\begin{abstract}
Background: Colorectal cancer is the most common gastrointestinal cancer in Oman with an increasing incidence. We here report the presenting features, treatment outcomes and survival in a University hospital in Oman and compare our data with regional and international studies. Materials and Methods: Medical records of patients with colorectal cancer were reviewed retrospectively between June 2000 and December 2013 and were followed until June 2014. Results: A total of 162 patients were diagnosed with colorectal cancer. The majority were males $(\mathbf{5 8 . 6 \%})$, with a median age of 56 years. Rectum was involved in $29.6 \%$ of patients, followed by ascending and sigmoid colon. The majority of patients had stage III $(42.6 \%)$ and stage IV $(32.7 \%)$ disease at presentation. K-Ras status was checked for 79 patients, and $41(51.9 \%)$ featured the wild type. Median relapse free survival was 22 months. Median overall survival for all patients was 43 months. Observed 5 year overall survival (OS) for stages I, II and III was $100 \%, 60 \%$ and $60 \%$ respectively. On Log rank univariate analysis, age, BMI, diabetes, hypertension, metformin use, stage, clinical nodal status for rectal cancer, pathological $T$ and nodal status, site of metastasis, surgical intervention, chemotherapy, radiotherapy, chemotherapy regimen, no of cycles of chemotherapy, response, RFS, site of recurrence and administration of $2^{\text {nd }}$ line chemotherapy were significant factors affecting OS. On Cox regression multivariate analysis none of the factors independently affected the OS. Conclusions: The majority of patients present with advanced disease and at young age. The survival rates are comparable to the published regional and international literature.
\end{abstract}

Keywords: Chemotherapy - colon cancer - metastasis - recurrence - Oman

Asian Pac J Cancer Prev, 16 (12), 4853-4858

\section{Introduction}

Colorectal cancer is the 3rd most common cancer in men and ranks $2^{\text {nd }}$ in women. The incidence is higher in developed countries compared to developing countries, however, the trend is changing (Ferlay et al., 2010; Jemal et al., 2011; Magaji et al., 2014). The majority of risk factors for colon and the rectal cancer are modifiable, and include the use of diets rich in saturated fats and obesity. Excessive consumption of increased amount of red meat either cooked, processed or prepared on charcoal fire are also known risk factors (Center et al., 2009; Jemal et al., 2011). As a result of these lifestyle factors, there is a significant variation in incidence and mortality rate from colorectal cancer across the globe (Center et al., 2009). However, there is a lag time between adoption of lifestyle changes and increase in the incidence. For example, for people who migrate from developing countries, the incidence remains low for a few decades compared to the natives of the developed countries (Nasseri et al., 2007; Ryu et al., 2013).
In the recent years it has been observed that the incidence of colorectal cancer in Arab population is increasing, and is variably attributed to lifestyle change and dietary habits (Rozen P et al., 2007; Amin et al., 2012; Al-Ahwal et al., 2013). Colorectal cancer is the $4^{\text {th }}$ most common cancer in Omani population (Mohammed et al., 2011). It is $2^{\text {nd }}$ common cancer in males and $4^{\text {th }}$ most common in females. The incidence has increased over the last 15 years (Mohammed et al., 2011).

Though the pattern and incidence for colorectal cancers from the developed countries has been reported in the literature, there is a scarcity of such information from the Arab world, and to date, no report from Oman. We report the clinico-pathological features, response to treatment and outcomes of colorectal cancer from Oman

\section{Materials and Methods}

The data were analyzed retrospectively. The diagnoses are stored electronically using international classification of diseases (ICD) version 9/10. Clinical data on consecutive

${ }^{1}$ Department of Medicine, ${ }^{2}$ Nursing Directorate, Sultan Qaboos University Hospital, ${ }^{3}$ College of Medicine and Health Sciences, Sultan Qaboos University, Muscat, Oman*For correspondence: bhagial@yahoo.com 
patients admitted to the hospital between June 2000 and December 2013, and diagnosed to have colon or rectal cancer at the Sultan Qaboos University hospital (SQUH) were retrieved. The hospital is one of the two hospitals providing cancer care in Sultanate of Oman. Some patients presented after the diagnosis elsewhere, however, the majority were diagnosed and treated at our hospital. For the patients who were diagnosed elsewhere, specimens were reviewed by the pathology department; in most cases for verification of diagnosis, immunohistochemistry (IHC) and K-ras status. Paraffin-embedded sections were sent to a reference laboratory abroad to determine the presence or absence of mutations on codon 12 and 13.

The medical records of all patients with a diagnosis of colorectal cancer were reviewed and information was extracted on a pre-designed database. Variables included demographic features, date of diagnosis, side of involvement; histopathological features, such as, the type; tumor size, lymph node involvement; tumor grade, etc. and radiological features, such as presence or absence of metastases. Pathological and clinical stage was determined using the $7^{\text {th }}$ edition of American Joint Committee on Cancer (AJCC) manual. Furthermore, response to treatment was determined by reviewing the $\mathrm{CT}$ scans and tumor marker levels. The date of last follow-up exam, date and site of relapse, and date of death, where relevant were recorded.

The date of last follow up exam for each patient was used to censor the data. The relapse/progression-free survival (RFS or PFS) was calculated from the date of diagnosis to the date of documented relapse/progression, similarly overall survival (OS) was calculated from the date of diagnosis to the date of death or last follow up where relevant. OS and RFS were determined using the Kaplan and Meir method; Cox proportional hazard model was used to compare the survival between different stages. Log rank analysis was used for univariate analysis while for multivariate analysis, Cox model was used. Statistical software package (SPSS version 19) was used for data analysis.

\section{Results}

A total of 162 patients were diagnosed to have colorectal cancer between June 2000 and December 31, 2013. The majority of the patients were males $(58.6 \%)$ and the median age at diagnosis was 56 years (range 18-80). The majority of the patients were older than 50 years $(61.1 \%)$, while a significant number $(11.1 \%)$ were younger than 30 years. Only $14(8.6 \%)$ patients had positive family history of colon cancer while 67 (47.9\%) had no family history while it was unknown in remaining $83(51.2 \%)$ patients. Median body mass index (BMI) was 24.6 (range 14-39.5). Of the 124 patients for whom BMI was available, 57 (46\%) were either overweight or obese. More than $50 \%$ patients had significant co-morbidities, such as diabetes mellitus or ischemic heart disease. Details are shown in Table 1.

Colon was the involved site in 114 patients, while, rectum was the involved site in $48(29.6 \%)$ patients. Details are shown in Table 2. The majority of patient had advanced stage disease at presentation. Sixty nine (42.6\%) patients had stage III disease at the time of diagnosis while $53(32.7 \%)$ patients had stage IV disease, liver being the most common site (22.8\%) of metastases (Table 2). K-Ras status was checked for 79 patients, 41 (51.9\%) had wild type while $38(48.1 \%)$ had mutation either on codon 12 or 13 .

\section{Treatment}

Out of 114 patients with colon cancer, 77 (67.4\%) received hemicolectomy as the primary surgical procedure. Out of 48 patients with rectal cancer, $20(41.7 \%)$ received abdomino-perineal resection as the definitive surgical procedure, of which 11 patients received neo-adjuvant chemo-radiotherapy before surgical resection. Details are shown in table 3 . Of the 32 patients with metastasis only to the liver at the time of diagnosis, 13 underwent either metastasectomy or a more extensive surgical resection either as a primary procedure or following a few cycles of chemotherapy (for details, please see Table 3 ).

Of all the patients, $74(45.7 \%)$ had adjuvant chemotherapy, $43(26.5 \%)$ were treated with palliative chemotherapy. Only 11 patients with rectal cancer were treated with neo-adjuvant chemo-radiotherapy others were treated in adjuvant or palliative setting. Twelve patients refused to have chemotherapy while 3 were not treated due to poor performance status. FOLFOX4 (oxaliplatin, leucovorin and fluorouracil) was the most commonly used first line chemotherapy regimen in 57 (35.2\%) patients, table 3 .

All 11 patients diagnosed to have stage I disease or carcinoma in situ (CIS) did not receive any adjuvant treatment. Out of 97 patients with stage II and III disease, rectum was involved in 34 patients. Of those 34 patients 28 patients received concurrent chemo-radiotherapy (11

\section{Table 1. Patient Characteristics (All Patients)}

\begin{tabular}{llc}
\hline Gender & & \\
\hline \multirow{5}{*}{ Age Range } & Male & $95(58.6)$ \\
& Median Age & $67(41.4)$ \\
& Less than 20 & 56 \\
& $21-30$ years & $1(0.6)$ \\
& $31-40$ years & $17(10.5)$ \\
& $41-50$ years & $15(9.3)$ \\
& 51-60 years & $31(19.1)$ \\
61-70 years & $45(27.8)$ \\
& $71-80$ years & $34(21.0)$ \\
Body Mass Index & Underweight & $19(11.7)$ \\
& Normal & $8(4.9)$ \\
& Overweight & $59(36.4)$ \\
& Obese & $30(18.5)$ \\
& Missing & $27(16.7)$ \\
& None & $38(23.5)$ \\
& One comorbid & $79(48.7)$ \\
& Two comorbids & $34(21.0)$ \\
& Three comorbids & $21(13)$ \\
& $>3$ comorbids & $20(12.3)$ \\
& Diabetes Mellitus & $8(4.9)$ \\
& Hypertension & $40(24.7)$ \\
& Heart Disease & $68(42.0)$ \\
& Patients on Metformin & $15(9.3)$ \\
& & $28(17.3)$ \\
\hline
\end{tabular}


Table 2. Site and Pathological Features

\begin{tabular}{|c|c|c|}
\hline Site of disease & \multicolumn{2}{|c|}{ Total No. 162} \\
\hline Rectum & \multicolumn{2}{|c|}{$48(29.6)$} \\
\hline Sigmoid colon & \multicolumn{2}{|c|}{$43(26.5)$} \\
\hline Ascending colon & \multicolumn{2}{|c|}{$34(21.0)$} \\
\hline Descending colon & \multicolumn{2}{|c|}{$29(17.9)$} \\
\hline Transverse colon & \multicolumn{2}{|c|}{$8(4.9)$} \\
\hline & Colon $(n=114)$ & Rectum $(n=48)$ \\
\hline \multicolumn{3}{|l|}{ Stage at presentation } \\
\hline Carcinoma in Situ & $2(1.8)$ & $0 \quad(0)$ \\
\hline Stage I & $6 \quad(5.3)$ & $3(6.3)$ \\
\hline Stage II & $17(14.9)$ & $11(22.9)$ \\
\hline Stage III & $46(40.4)$ & $23(47.9)$ \\
\hline Stage IV & $42(36.8)$ & $11(22.9)$ \\
\hline Missing data & $1(0.9)$ & $0 \quad(0)$ \\
\hline \multicolumn{3}{|l|}{ Differentiation } \\
\hline Well Differentiated & $7 \quad(6.1)$ & $2(4.2)$ \\
\hline Moderately Differentiated & $84(73.7)$ & $41(85.4)$ \\
\hline Poorly Differentiated & $22(19.3)$ & $5(10.4)$ \\
\hline Missing data & $1(0.9)$ & $0 \quad(0)$ \\
\hline \multicolumn{3}{|l|}{ Pathological Tumor Size } \\
\hline pTis & $2(1.8)$ & $2(4.2)$ \\
\hline pT1 & $4 \quad(3.5)$ & $0 \quad(0)$ \\
\hline pT2 & $8(7.0)$ & $7(14.6)$ \\
\hline pT3 & $44(38.6)$ & $19(39.6)$ \\
\hline pT4 & $29(25.4)$ & $9(18.8)$ \\
\hline Not-Available & $27(23.7)$ & $11(22.9)$ \\
\hline \multicolumn{3}{|l|}{ Pathological Node Status } \\
\hline $\mathrm{pNO}$ & $28(24.6)$ & $16(33.3)$ \\
\hline $\mathrm{pN} 1$ & $31(27.2)$ & $15(31.3)$ \\
\hline pN2 & $28(24.6)$ & $5(10.4)$ \\
\hline Not-Available & $27(23.7)$ & $12(25.0)$ \\
\hline \multicolumn{3}{|l|}{ Synchronous Metastasis } \\
\hline Liver only & $26(22.8)$ & $6(12.5)$ \\
\hline Peritoneum & $5(4.4)$ & $3(6.3)$ \\
\hline Liver and Lung & $4 \quad(3.5)$ & 1 (2.1) \\
\hline Lung & $2(1.8)$ & 1 (2.1) \\
\hline Adnexa & 3 (2.6) & $0 \quad(0)$ \\
\hline Liver and ovary & $1(0.9)$ & $0 \quad(0)$ \\
\hline Peritoneum and Lung & $1 \quad(0.9)$ & $0 \quad(0)$ \\
\hline Missing & $1 \quad(0.9)$ & $0 \quad(0)$ \\
\hline No-Metastasis & $72(63.2)$ & $37(77.1)$ \\
\hline \multicolumn{3}{|l|}{ K-Ras Status } \\
\hline Wild Type & $28(24.6)$ & $13(27.1)$ \\
\hline Mutant Type & $30(26.3)$ & $8(16.7)$ \\
\hline Not Checked & $55(48.2)$ & $26(54.2)$ \\
\hline
\end{tabular}

in neo-adjuvant setting while 17 in adjuvant setting) while remaining 3 had short course neo-adjuvant radiotherapy; 2 refused for any treatment while 1 was not treated due to poor performance status. Of the remaining 63 patients with colon cancer, FOLFOX4 was administered to 38 patients, 15 patients received XELOX (Capecitabine and Oxaliplatin), 18 were treated with oral capecitabine and 16 were treated with infusional fluorouracil (Mayo protocol). 7 patients refused to take adjuvant treatment, 1 was not treated due complications after surgery, 1 due to poor performance status, and 1 patient was treated with disease in place as it was not amenable to surgery.

Rectum was primary site of involvement in 10 of 53 patients with stage IV disease at the time of diagnosis. Three patients refused chemotherapy, while 2 were not treated due to poor PS. Nearly $2 / 3^{\text {rd }}$ patients with metastatic disease 37 (69.8\%) had some kind of surgical
Table 3. Treatment Offered

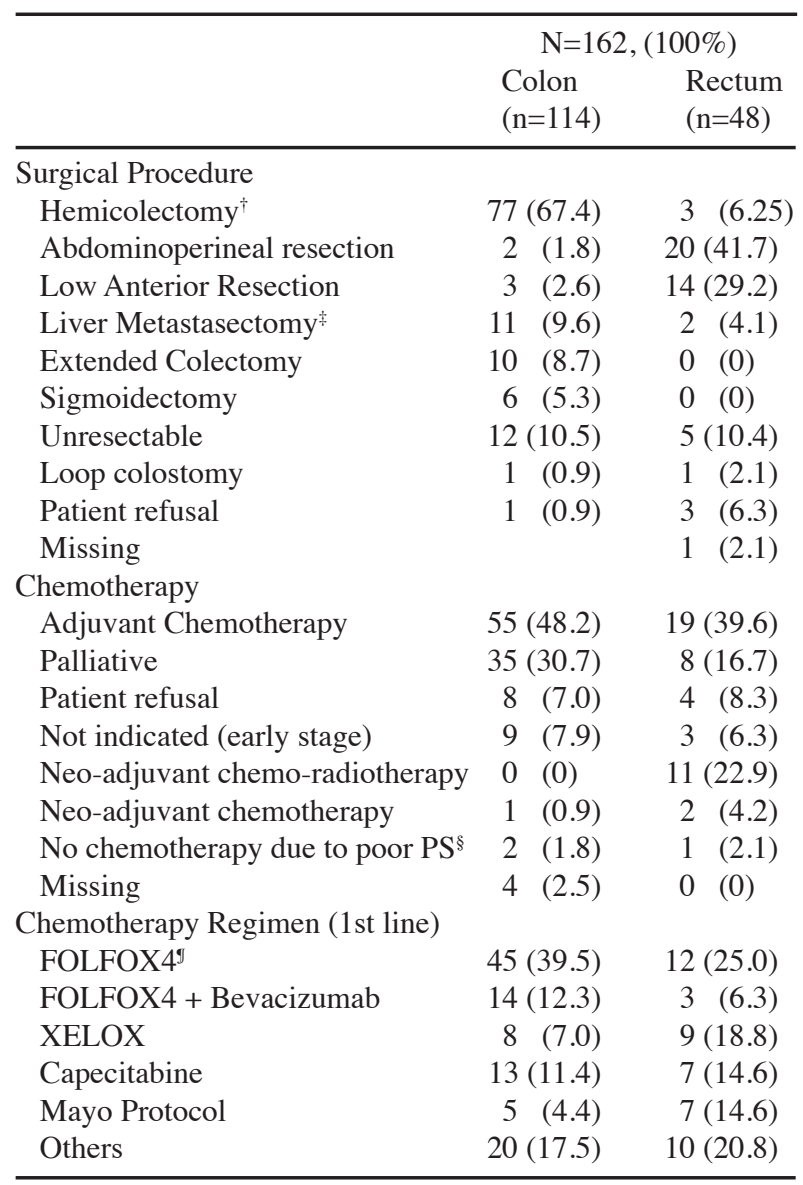

12 patients had hemicolectomy along with liver metastasectomy (either 1 or 2 stage procedure), while 1 had RFA of liver lesion along with hemicolectomy; most patients were treated with neo-adjuvant chemotherapy before liver metastasectomy; ${ }^{\S} \mathrm{PS}=$ Performance Status; ${ }^{\mathrm{g}} \mathrm{FOLFOX} 4$ (oxaliplatin, leucovorin and fluorouracil)

A)

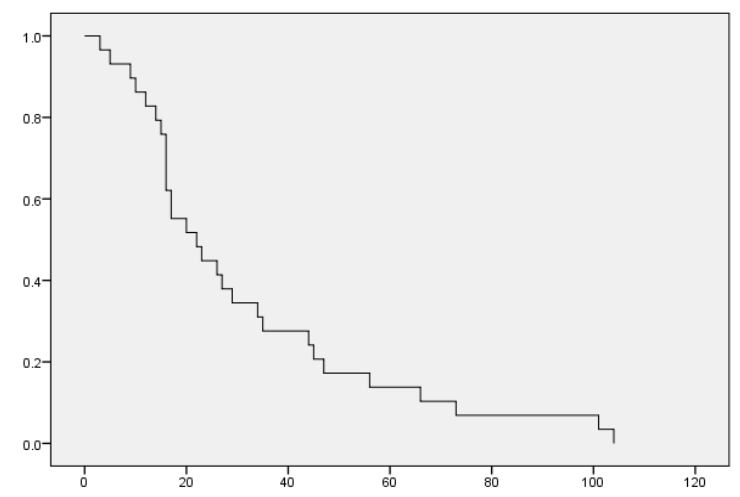

B)

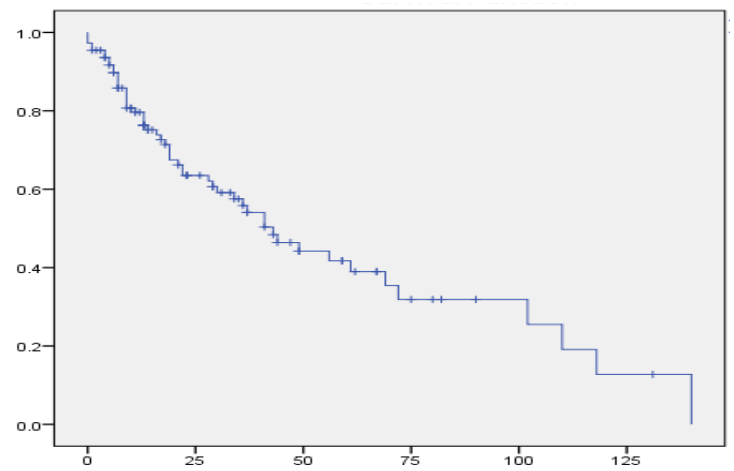

Figure 1. A) Recurrence Free Survival in Months for Patients with Non-metastatic Disease at Presentation; B) Overall Survival in Months for All Patients 


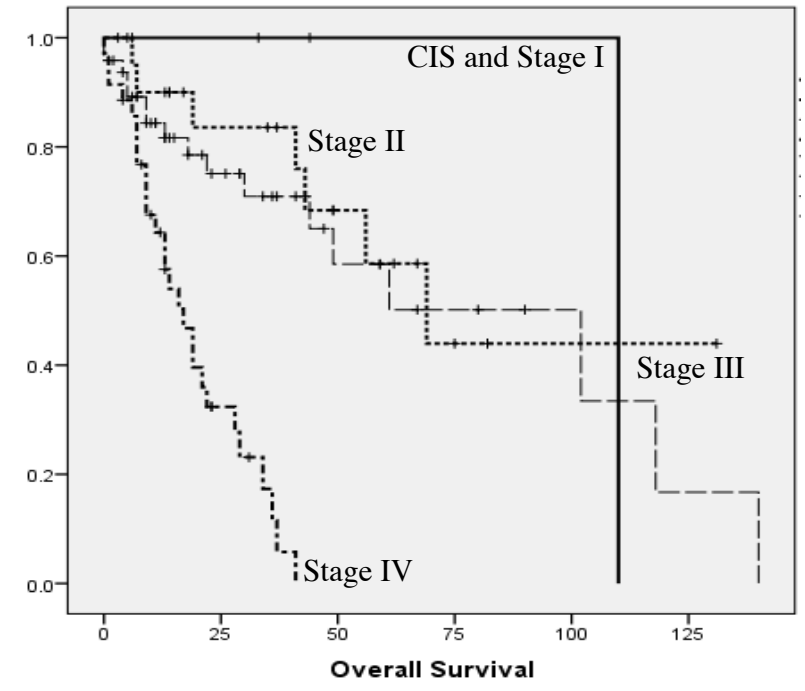

Figure 2. Overall Survival for All Patients According to Stage

intervention, and out of those 10 patients had complete surgical resection of disease during the treatment trajectory. FOLFOX4 was most common administered regimen (Table 3). Majority of patients received multiple lines of treatment (range 1-6 lines). Regorafenib was used for 6 patients at some point of the treatment as well.

Median number of chemotherapy cycles in first line was 8 (range 1-18), dose delays were documented in 50 (30.9\%) patients, mainly due to cytopenias and diarrhea, while grade III diarrhea and cytopenias were most common side effects experienced by the patients, $13.6 \%$ and $14.2 \%$ respectively.

\section{Recurrence}

Of 109 patients with non-metastatic disease at presentation, disease recurrence was documented in 39 $(35.8 \%)$ patients. Twenty eight patients had stage III at the diagnosis, 6 had stage II and 4 had stage I disease. Majority has recurrence to liver 11 (28.2) followed by lung $9(23.0 \%)$. Majority of patients with recurrence were treated with chemotherapy only $20(51.2 \%), 7$ (17.9\%) also had surgical resection followed by chemotherapy, $6(15.3 \%)$ underwent surgical resection only, 5 (12.8\%) received best supportive care, and $1(2.5 \%)$ had radiofrequency ablation of liver lesion.

Median RFS was 22 months (range 3-104), Figure 1. On univariate log rank analysis age $(\mathrm{p}<0.001)$, BMI $(\mathrm{p}<0.001)$, absence of ischemic heart disease $(\mathrm{p}=0.02)$, tumor location $(\mathrm{p}=0.004)$, surgery $(\mathrm{p}<0.001)$, adjuvant chemotherapy ( $\mathrm{p} 0.004$ ), chemotherapy regimen $(\mathrm{p}<0.001)$, dose delays ( $\mathrm{p} 0.01)$ and adverse events post chemotherapy $(\mathrm{p}<0.001)$ were significantly associated with RFS while gender (p 0.72), family history (p 0.06), comorbid condition (p 0.56), metformin use (p 0.76), differentiation ( $\mathrm{p} 0.67$ ), disease stage (p 0.36), clinical $\mathrm{T}(\mathrm{p}=0.11)$ or nodal status $(\mathrm{p}=0.22)$ for rectal cancer, pathological T stage (p 0.11), pathological nodal status (p 0.14) and K-Ras status (p 0.83)were not associated significantly with RFS.
On the day of data censorship and median follow-up of 18.5 months (range 1-140), 61 (37.7\%) are in remission, $43(26.5 \%)$ patients died of progressive disease, $3(1.9 \%)$ patient died of therapy related adverse events, 7 (4.3\%) patient died of causes not related to the disease or therapy, $2(1.2 \%)$ patients are on best supportive care, 21 (13.0\%) patients are on treatment actively for their disease while data are not available for remaining 25 (15.4\%) patients.

Median OS for all patients was 43 months (range 0 -146), with 5 year OS of $42 \%$. Observed 5 year OS for stage I, II and III was $100 \%, 60 \%$ and $60 \%$ respectively while all patients with stage IV disease at diagnosis died. The median survival for patients with stage IV disease was 17 months (Figure 2).

On Log rank univariate analysis, age at diagnosis $(p \leq 0.001)$, BMI $(p \leq 0.001)$, having diabetes ( $p 0.05)$, hypertension ( $\mathrm{p} 0.03$ ), metformin use ( $\mathrm{p} 0.04)$, stage at the diagnosis $(p \leq 0.001)$, clinical nodal status for rectal cancer $(\mathrm{p}=0.003)$, pathological $\mathrm{T}(\mathrm{p}=0.003)$ and nodal status $(\mathrm{p} \leq 0.01)$, site of metastasis $(\mathrm{p} \leq 0.001)$, surgical intervention $(\mathrm{p} \leq 0.001)$, administration of chemotherapy $(p \leq 0.001)$ and radiotherapy ( $p 0.04)$, chemotherapy regimen (p 0.001), no of cycles of chemotherapy $(p \leq 0.001)$, response to chemotherapy $(p \leq 0.001), R F S$ $(\mathrm{p} \leq 0.01)$, site of recurrence $(\mathrm{p} \leq 0.001)$ and administration of $2^{\text {nd }}$ line chemotherapy $(\mathrm{p} \leq 0.001)$ were significant factors affecting OS. On cox regression multivariate analysis none of those mentioned factors affected the OS significantly.

\section{Discussion}

The present study indicates that almost $1 / 5^{\text {th }}$ of the patients were diagnosed to have colo-rectal cancer below the age of 40 years (Table 1). The age at diagnosis is younger than reported from Kingdom of Saudi Arabia (KSA), Egypt, Iran, Malaysia and Pakistan but older than that reported from United Arab Emirates (UAE) (AlShamsi et al., 2003; El-Bolkainy et al., 2006; Aljebreen, 2007; Shaikh et al., 200; Bhurgri et al., 2011; Amin et al., 2012; Hajmanoochehri et al., 2014; Magaji et al., 2014). It would be important to note that a number of Omani patients were also included in cohort of patients reported by Al-Shamsi et al from UAE, but authors did not specify the number of Omani patients or segregated them in their report (Al-Shamsi et al., 2003). Diagnosis of colorectal cancer at younger age is not common but has been reported in the literature (Karnak et al., 1999; Chen et al., 2001; Khurshed et al., 2007 Oct-Dec; Sultan et al., 2010). One possible reason for diagnosis at younger age may be due to young age structure of Oman. Only $5.1 \%$ population is above the age of 60 (Mohammed et al., 2011).

Risk of developing colorectal cancer is high for patients with a positive family history or underlying predisposing condition like ulcerative colitis. Only 14 (8.6\%) patients had positive family history in our data, however, it is important to note that for $65(40.1 \%)$ patients, the data were unknown owing to the retrospective nature of the study (Table 1). Furthermore, in 3 families strong suspicion of familial adenomatous polyposis was raised clinically, but could not be confirmed due to reluctance of apparently healthy family members for 
screening colonoscopy. For the reasons stated above, the figure of $8.6 \%$ showing positive family history might be an underestimate.

Rectum was involved site in $29.6 \%$ of cases, followed by sigmoid colon, ascending colon, descending colon and transverse colon. This pattern of affliction conforms to the data published from neighboring Arab countries (Al-Shamsi SR et al., 2003; Mahdavinia et al., 2005; El-Bolkainy TN et al., 2006 Sep; Aljebreen, 2007; Amin TT et al., 2012; Veruttipong D et al., 2012 Aug), Iran and Pakistan (Bhurgri Y et al., 2011; Hajmanoochehri et al., 2014). A similar trend was seen in the western world a few years back, but the site of involvement for colonic cancer is now increasing (Ponz de Leon et al., 2004; Phipps et al., 2012).

The advanced stage at presentation (42.6\%-stage III and $32.7 \%$ - stage IV) is similar to data published from Egypt, KSA and Jordan (El-Bolkainy et al., 2006; Aljebreen, 2007; Sultan et al., 2010; Al-Ahwal et al., 2013) but at variance with the data published from Western Europe and North America (Ponz de Leon et al., 2004; Lopez-Abente et al., 2010; Phipps et al., 2012). Early stage at presentation from the western world reflects the success of screening programs (Lopez-Abente et al., 2010; Elmunzer et al., 2012; McClements et al., 2012; Phipps et al., 2012).

Although a significant number of patients presented with advanced stage disease, however, the treatment was administered in conformity with the guidelines for the stage (Labianca et al., 2010; Benson et al., 2013). Surgery was considered adequate if the resection margins were negative and adequate lymph nodes were sampled. Hemicolectomy or sigmoidectomy were the most common surgical procedures for colon cancer, and more than $50 \%$ of the patients received neo-adjuvant chemo-radiotherapy for rectal cancer prior to APR. Of 109 patients with non-metastatic disease $78(71.5 \%)$ were treated with chemotherapy in adjuvant setting, FOLFOX4 being the most common regimen. FOLFOX4, capecitabine and infusional fluorouracil are recognized and well known regimens for adjuvant treatment for colorectal cancer (André et al., 2004; Twelves et al., 2005; Chiu et al., 2013; Duran et al., 2014). Adjuvant treatment for stage II colon cancer has been debated since long. Most of the patients with stage II colon cancer do not benefit from adjuvant chemotherapy except few with associated risk factors like inadequate lymph nodes sampling, positive surgical margins, T4 disease at presentation, perineural invasion or poor differentiation on pathology (Hassan et al., 2015; Kucukzeybek et al., 2015). All patients with stage II disease were treated with some form of adjuvant chemotherapy in our cohort.

Advanced age and comorbids are considered indicators of poor outcome. In this study, age was one of the significant factors affecting the RFS as well OS which is similar to many previous studies (Al-Ahwal et al., 2013). Similarly tumor location, rectum as primarily involved site and tumor differentiation have been shown to affect the outcome of patients with CRC in many studies (AlAhwal et al., 2013; Omranipour et al., 2014) but not in our cohort. We cannot explain the positive effect of diabetes and hypertension on survival in our population. Diabetes is considered to increase the risk for malignancies (Tseng, 2012).

Of 53 patients with metastatic disease, liver metastasectomy was performed at some stage for 12 patients, which is known to improve overall survival for stage IV colorectal cancer (Alsina and Choti, 2011; NCCN, 2014).

Molecular expression of Ras status is associated with recurrence, survival and benefit of adjuvant chemotherapy regimens as seen in several large randomized studies (Bozkurt et al., 2014). No relation was noticed with wild or mutant K-Ras status with RFS or OS in our cohort which may be explained by small sample size.

Various studies have shown beneficial effect of metformin on cancer especially colon cancer (Tseng, 2012; Nangia-Makker et al., 2014). In our cohort patients who were using metformin for their diabetes control had lower chance of disease recurrence or from dying secondary to the disease.

Survival for Omani patient was similar as reported by the EUROCARE-4 study by Sant et al(Sant et al., 2009). The 5 year OS observed in that study for different European countries varied between 38.7 and $57.7 \%$ which was $42 \%$ in our cohort. With better access and improved care for cancer patients improved survival trend has been witnessed in the Europe but still it was variable among different countries and varied between as low as $45.2 \%$ to $63.8 \%$ with mean survival of $56.2 \%$ between period 2000-2002 which is low as compare to US data (65.5\%)(Verdecchia et al., 2007). The variation in survival for same caner among different countries is well known and depends upon the cancer registry, stage at presentation, access to medical care, availability of care and screening protocol (Gatta et al., 2000; Ciccolallo et al., 2005). Keeping in view all these factors the survival for our patient matches with western countries and is better than reported from neighboring country (Al-Ahwal et al., 2013).

The implementation of screening programs has resulted not only in a decrease in incidence of colorectal cancer but also improves the overall survival (Elmunzer et al., 2012; McClements et al., 2012; Schoen et al., 2012). Recommended age to begin screening is 50 years in most of guidelines, which may have to be looked carefully in the middle east, as most patients present at age less than 50 years. Furthermore, it may be difficult to suggest the need of a screening program in Oman, where only $8.6 \%$ of the patients had a positive family history. However, this is first report on CRC outcome from the country and sets the benchmark for future studies to compare

In conclusion colorectal cancer is being diagnosed at younger age, at an advanced stage but the overall survival matches the international literature.

\section{References}

Al-Ahwal MS, Shafik YH, HM A-A (2013). First national survival data for colorectal cancer among Saudis between 1994 and 2004: what's next? BMC Public Health, 13, 73.

Al-Shamsi SR, Bener A, Al-Sharhant M, et al (2003). 
Clinicopathological pattern of colorectal cancer in the United Arab Emirates. Saudi Med J, 24, 518-22.

Aljebreen AM (2007). Clinico-pathological patterns of colorectal cancer in Saudi Arabia: younger with an advanced stage presentation. Saudi J Gastroenterol, 13, 84-7.

Alsina J, Choti MA (2011). Liver-directed therapies in colorectal cancer. Semin Oncol, 38, 561-7.

Amin TT, Suleman W, Al Taissan AA, et al (2012). Patients' profile, clinical presentations and histopathological features of colorectal cancer in Al Hassa region, Saudi Arabia. Asian Pac J Cancer Prev, 13, 211-6.

André T, Boni C, Mounedji-Boudiaf L, et al (2004). Oxaliplatin, fluorouracil, and leucovorin as adjuvant treatment for colon cancer. New England J Med, 350, 2343-51.

Benson AB, 3rd, Bekaii-Saab T, Chan E, et al (2013). Localized colon cancer, version 3.2013: featured updates to the NCCN Guidelines. J Natl Compr Canc Netw, 11, 519-28.

Bhurgri Y, Khan T, Kayani N, et al (2011). Incidence and current trends of colorectal malignancies in an unscreened, low risk Pakistan population. Asian Pac J Cancer Prev, 12, 703-8.

Bozkurt O, Inanc M, Turkmen E, et al (2014). Clinicopathological characteristics and prognosis of patients according to recurrence time after curative resection for colorectal cancer. Asian Pac J Cancer Prev, 15, 9277-81.

Center MM, Jemal A, Smith RA, et al (2009). Worldwide variations in colorectal cancer. A Cancer J Clin, 59, 366-78.

Chen LK, Hwang SJ, Li AF, et al (2001). Colorectal cancer in patients 20 years old or less in Taiwan. South Med J,94, 1202-5.

Chiu J, Tang V, Leung R, et al (2013). Efficacy and tolerability of adjuvant oral capecitabine plus intravenous oxaliplatin (XELOX) in Asian patients with colorectal cancer: 4-year analysis. Asian Pac J Cancer Prev, 14, 6585-90.

Ciccolallo L, Capocaccia R, Coleman MP, et al (2005). Survival differences between European and US patients with colorectal cancer: role of stage at diagnosis and surgery. Gut, 54, 268-73.

Duran AO, Karaca H, Besiroglu M, et al (2014). XELOX plus bevacizumab vs. FOLFIRI plus bevacizumab treatment for firstline chemotherapy in metastatic colon cancer: a retrospective study of the anatolian society of medical oncology. Asian Pac J Cancer Prev, 15, 10375-9.

El-Bolkainy TN, Sakr MA, Nouh AA, et al (2006 Sep). A comparative study of rectal and colonic carcinoma: demographic, pathologic and TNM staging analysis. $J$ Egypt Natl Canc Inst, 18, 258-63.

Elmunzer BJ, Hayward RA, Schoenfeld PS, et al (2012). Effect of flexible sigmoidoscopy-based screening on incidence and mortality of colorectal cancer: a systematic review and metaanalysis of randomized controlled trials. PLoS Med,9, 1001352.

Ferlay J, Shin HR, Bray F, et al (2010). Estimates of worldwide burden of cancer in 2008: GLOBOCAN 2008. Int J Cancer, 127, 2893-917.

Gatta G, Capocaccia R, Sant M, et al (2000). Understanding variations in survival for colorectal cancer in Europe: a EUROCARE high resolution study. Gut, 47, 533-8.

Hajmanoochehri F, Asefzadeh S, Kazemifar AM, et al (2014). Clinicopathological features of colon adenocarcinoma in Qazvin, Iran: a 16 year study. Asian Pac J Cancer Prev, 15, 951-5.

Hassan AS, Naicker M, Yusof KH, et al (2015). Prognostic factors and the role of adjuvant chemotherapy in post-curative surgery for dukes $\mathrm{B}$ and $\mathrm{C}$ colon cancers and survival outcomes: a malaysian experience. Asian Pac J Cancer Prev, 16, 2237-43.

Jemal A, Bray F, Center MM, et al (2011). Global cancer statistics. Ca: A Cancer J Clin, 61, 69-90.

Karnak I, Ciftci AO, Senocak ME, et al (1999). Colorectal carcinoma in children. J Pediatr Surg, 34, 1499-504.

Khurshed A,Ahmed R, Y.B (2007 Oct-Dec).Primary gastrointestinal malignancies in childhood and adolescence--an Asian perspective. Asian Pac J Cancer Prev, 8, 613-7.

Kucukzeybek Y, Dirican A, Demir L, et al (2015). Adjuvant chemotherapy and prognostic factors in stage II colon cancer- izmir oncology group study. Asian Pac J Cancer Prev, 16, 2413.

Labianca R, Nordlinger B, Beretta GD, et al (2010). Primary colon cancer: ESMO Clinical Practice Guidelines for diagnosis, adjuvant treatment and follow-up. Ann Oncol, 21, 70-7.

Lopez-Abente G, Ardanaz E, Torrella-Ramos A, et al (2010). Changes in colorectal cancer incidence and mortality trends in Spain. Ann Oncol, 21, 76-82.

Magaji BA, Moy FM, Roslani AC, et al (2014). Descriptive epidemiology of colorectal cancer in University Malaya Medical Centre, 2001 to 2010. Asian Pac J Cancer Prevention, 15, 6059-64.

Mahdavinia M, Bishehsari F, Ansari R, et al (2005). Family history of colorectal cancer in Iran. BMC Cancer, 5, 112.

McClements PL, Madurasinghe V, Thomson CS, et al (2012). Impact of the UK colorectal cancer screening pilot studies on incidence, stage distribution and mortality trends. Cancer Epidemiol, 36, 232-42.

Nangia-Makker P, Yu Y, Vasudevan A, et al (2014). Metformin: a potential therapeutic agent for recurrent colon cancer. PloS One, 9, 84369.

Nasseri K, Mills PK, M A (2007). Cancer incidence in the middle Eastern population of California, 1988-2004. Asian Pac J Cancer Prev, 8, 405-11.

NCCN. 2014. NCCN Clinical practice guidelines in oncology. Colon cancer version 2.2015 [Online]. National comprehensive cancer network. Available: http://www.nccn.org/professionals/ physician_gls/f_guidelines.asp [Accessed 28/11/2014.

Omranipour R, Mahmoodzadeh H, Safavi F (2014). Prevalence of local recurrence of colorectal cancer at the Iranian cancer institute. Asian Pac J Cancer Prev, 15, 8587-9.

Phipps AI, Scoggins J, Rossing MA, et al (2012). Temporal trends in incidence and mortality rates for colorectal cancer by tumor location: 1975-2007. Am J Public Health, 102, 1791-7.

Ponz de Leon M, Marino M, Benatti P, et al (2004). Trend of incidence, subsite distribution and staging of colorectal neoplasms in the 15-year experience of a specialised cancer registry. Ann Oncol, 15, 940-6.

Rozen P, Rosner G, Liphshitz I, et al (2007). The changing incidence and sites of colorectal cancer in the Israeli Arab population and their clinical implications. Int J Cancer, 120, 147-51.

Ryu SY, Crespi CM, Maxwell AE (2013). Colorectal cancer among Koreans living in South Korea versus California: incidence, mortality, and screening rates. Ethn Health [Epub ahead of print].

Sant M, Allemani C, Santaquilani M, et al (2009). EUROCARE-4. Survival of cancer patients diagnosed in 1995-1999. Results and commentary. Eur J Cancer, 45, 931-91.

Schoen RE, Pinsky PF, Weissfeld JL, et al (2012). Colorectal-cancer incidence and mortality with screening flexible sigmoidoscopy. N Engl J Med, 366, 2345-57.

Shaikh AJ, Raza S, Shaikh AA, et al (2009 Jul-Sep). Demographics, pathologic patterns and long-term survival in operable colon cancers: local experience in Pakistan. Asian Pac J Cancer Prev, 10, 361-4.

Sultan I, Rodriguez-Galindo C, El-Taani H, et al (2010). Distinct features of colorectal cancer in children and adolescents: a population-based study of 159 cases. Cancer, 116, 758-65.

Tseng C-H (2012). Diabetes, metformin use, and colon cancer: a population-based cohort study in Taiwan. European $J$ Endocrinol, 167, 409-16.

Twelves C, Wong A, Nowacki MP, et al (2005). Capecitabine as adjuvant treatment for stage III colon cancer. New England J Med, 352, 2696-704.

Verdecchia A, Francisci S, Brenner H, et al (2007). Recent cancer survival in Europe: a 2000-02 period analysis of EUROCARE-4 data. Lancet Oncol, 8, 784-96.

Veruttipong D, Soliman AS, Gilbert SF, et al (2012 Aug). Age distribution, polyps and rectal cancer in the Egyptian population-based cancer registry. World J Gastroenterol, 18, 3997-4003. 